\title{
Thromboembolic Events Secondary to Endoscopic Cyanoacrylate Injection: Can We Foresee Any Red Flags?
}

\author{
Yujen Tseng $\left(\mathbb{D},{ }^{1}\right.$ Lili Ma, ${ }^{2}$ Tiancheng Luo, ${ }^{1}$ Xiaoqing Zeng, ${ }^{1}$ Yichao Wei, ${ }^{1}$ Ling Li, ${ }^{3}$ \\ Pengju Xu $\mathbb{D}^{4},{ }^{4}$ and Shiyao Chen ${ }^{5}{ }^{5}$ \\ ${ }^{1}$ Department of Gastroenterology, Zhongshan Hospital, Fudan University, Shanghai, China \\ ${ }^{2}$ Department of Endoscopy Center, Zhongshan Hospital, Fudan University, Shanghai, China \\ ${ }^{3}$ Department of Geriatrics, Zhongshan Hospital, Fudan University, Shanghai, China \\ ${ }^{4}$ Department of Radiology, Zhongshan Hospital, Fudan University, Shanghai, China \\ ${ }^{5}$ Department of Gastroenterology, Endoscopy Center and Evidence-Based Medicine Center, Zhongshan Hospital, \\ Fudan University, Shanghai, China \\ Correspondence should be addressed to Shiyao Chen; chen.shiyao@zs-hospital.sh.cn
}

Received 31 October 2017; Revised 20 January 2018; Accepted 31 January 2018; Published 3 April 2018

Academic Editor: Fernando G. Romeiro

Copyright (C) 2018 Yujen Tseng et al. This is an open access article distributed under the Creative Commons Attribution License, which permits unrestricted use, distribution, and reproduction in any medium, provided the original work is properly cited.

Background. Gastric varices (GV) are associated with high morbidity and mortality in patients with portal hypertension. Endoscopic cyanoacrylate injection is the first-line recommended therapy for GV obliteration. This study aims to explore the reason behind related adverse events and better prevent its occurrence. Methods. A retrospective case series study was conducted from January 1, 2013, to December 31,2016, to identify patients who experienced severe adverse events secondary to endoscopic cyanoacrylate injection. A literature review of similar cases was performed on two medical databases, Medline and Embase. Results. A total of 652 patients underwent cyanoacrylate injection at our center within the study duration. Five cases of severe adverse events related to the use of tissue adhesives were identified. Detailed clinical presentation, patient treatment, and outcomes were reviewed and analyzed. Twenty-seven similar cases were identified based on the literature review providing further insight into the study. Conclusion. Although rare in incidence, systemic embolism associated with cyanoacrylate injection is often fatal or debilitating. This report may raise awareness in treatment protocol, including the necessity of preoperative angiographic studies, to avoid similar adverse events in clinical practice.

\section{Introduction}

Variceal hemorrhage is a fatal presentation of portal hypertension, commonly seen in patients with decompensated cirrhosis. Current treatment protocol for gastroesophageal varices includes primary prophylaxis, management of acute bleeding, and secondary prophylaxis [1]. According to the Baveno VI consensus, a combination of nonselective beta blockers (NSBB) and endoscopic variceal ligation (EVL) for esophageal varices and cyanoacrylate injection for gastric varices are recommended as first-line therapy [2]. Compared to esophageal varices, gastric varices are lower in prevalence but are associated with a higher risk of hemorrhage and mortality [3]. The use of $N$-butyl-2-cyanoacrylate (NB2CYA) for gastric variceal obliteration was first reported in
1986 and is currently well recognized as first-line therapy with a high hemostasis rate [4-6]. Large cohort studies have demonstrated the safety and efficacy of cyanoacrylate injection; however others have highlighted individual adverse events [7-9]. Occurrence of systemic embolization is often associated with patient morbidity and mortality. We hereby report a series of adverse events associated with cyanoacrylate injection for the treatment of gastric varices.

\section{Methods}

A retrospective case series study was conducted at a tertiary hospital. The hospital database was reviewed; approval was granted by the hospital's institutional review board (IRB). All patients who underwent endoscopic procedure had 
TABLE 1: Summary of patient characteristics, preoperative management, endoscopic findings, and subsequent treatment.

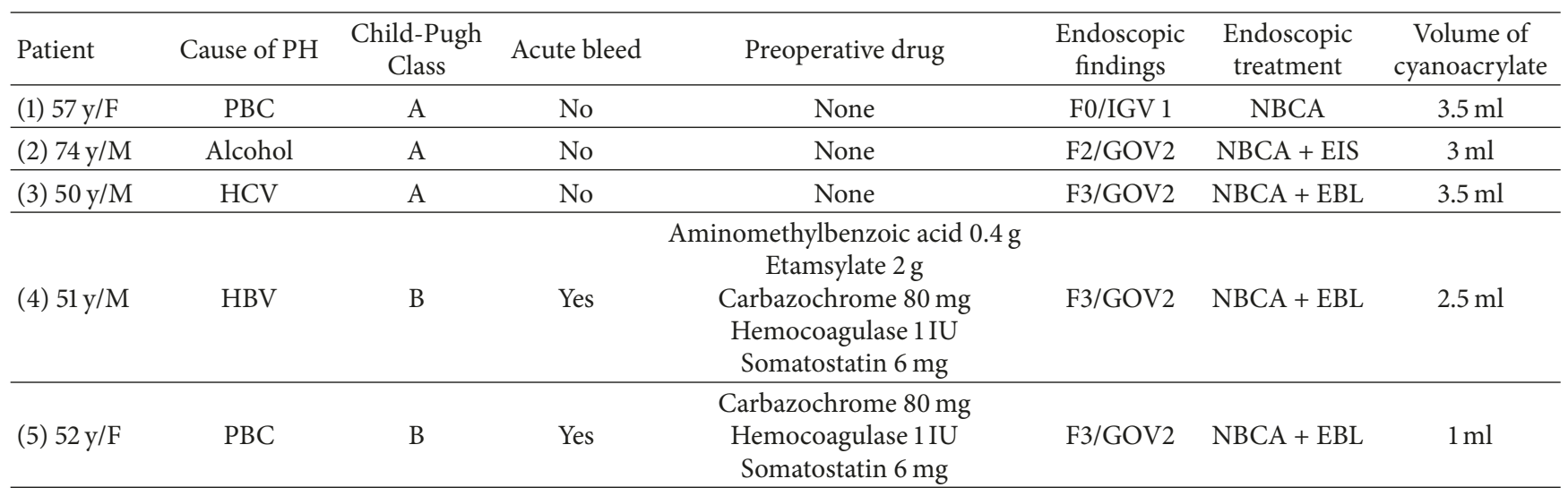

signed informed consent acknowledging the purpose and risk associated with the intervention. We included (1) patients with gastric varices with or without concurrent esophageal varices treated with injection of $\mathrm{N}$-butyl-cyanoacrylate and (2) patients who experienced severe adverse events (SAE) associated with cyanoacrylate injection within 48 hours of the endoscopic procedure. SAE was defined as occurrence of death, life-threatening disability, or permanent deficit, resulting in a prolonged hospital stay.

All endoscopic procedures were commenced after an overnight fast. First, a routine endoscopy exam was performed to assess the extent of gastroesophageal varices that were classified according to Sarin's classification. Concurrent esophageal varices were graded according to the Japanese Society of Portal Hypertension [10]. Each patient received individualized therapy as deemed fit by the operator. Gastric varices were uniformly treated via the sandwich technique, which starts with an injection of lauromacrogol (Tianyu Pharmaceutical, Zhejiang, China), followed by Nbutyl cyanoacrylate (Beijing Suncon Medical Adhesive, Beijing, China), and then finished with flush of lauromacrogol [11]. The number of injection sites and volume of lauromacrogol and cyanoacrylate used directly correlated with the size of the varix. Multiple injection sites were chosen in attempt to obliterate the varix or varices in one session. Volume of lauromacrogol used ranged from 2 to $10 \mathrm{ml}$, while that of cyanoacrylate ranged from 0.5 to $2 \mathrm{ml}$, per injection site. Concurrent esophageal varices were treated with either endoscopic band ligation (EBL) or endoscopic sclerotherapy injection (EIS) determined by the operator.

Patients were hospitalized for postoperative observations for 24-48 hours. Any occurrence of severe adverse events (SAE), as previously defined, was recorded. Treatment and patient response secondary to the adverse events were documented. Patient follow-ups were accomplished via telephone interviews or out-patient services to determine survival or further complications.

A literature review of case reports on adverse events related to cyanoacrylate injection was also conducted, specifically, occurrence of embolic or infarction events. Detailed search strategy of Medline (R), from 1946 to present with daily updates, and Embase, from 1974 to March 20, 2017, is provided in the Appendix.

\section{Results}

A thorough review of the inpatient and endoscopy database was carried out from January 1, 2013, to December 31, 2016. A total of 652 patients who underwent N-butyl-cyanoacrylate (NBCA) injection as secondary prophylaxis for gastric variceal hemorrhage were identified. Based on the a priori established inclusion criteria, the detailed hospital record and treatment protocol of 5 patients were reviewed for the purpose of this study. Three of the five patients were male, ranging from 50 to 74 years. The cause of cirrhosis was PBC in the two female patients, while the remaining were due to $\mathrm{HBV}, \mathrm{HCV}$, or alcohol, respectively. Three patients were classified as Child-Pugh Class A, while the remainder were Child-Pugh Class B. Two of the five patients were admitted to our hospital due to an episode of acute variceal hemorrhage, while others had either achieved hemodynamic stability or were admitted for a follow-up endoscopic examination. Prior to the procedure, two patients (patients (4) and (5)) received a combination of hemostatic agents and somatostatin. None of the patients had concurrent HCC or hepatic encephalopathy. Detailed patient characteristics are summarized in Table 1.

Based on the findings of the routine endoscopy, one patient had IGV Type 1, one had GOV Type 1, while three had GOV Type 2 (Figure 1). All gastric varices were treated with the sandwich technique injection of lauromacrogol and cyanoacrylate. The total volume of cyanoacrylate used ranged from 1.0 to $3.5 \mathrm{ml}$ (average $2.7 \mathrm{ml}$ ), without exceeding $1.5 \mathrm{ml}$ per injection site. Patients with concurrent esophageal varices were treated with either endoscopic band ligation (EBL) or endoscopic injection sclerotherapy (EIS).

One female patient (patient (1)) suffered from cardiac arrest during the procedure. The bedside echocardiogram revealed an enlarged right ventricle and right atrium, widened vena cava, and shrunken left ventricle. Despite aggressive measures including drug and equipment resuscitation, the patient did not survive. Patient (2) experienced fever, severe abdominal pain, and rebound tenderness after the 


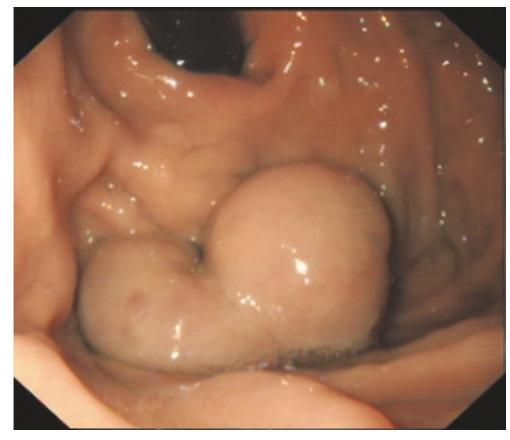

(a)

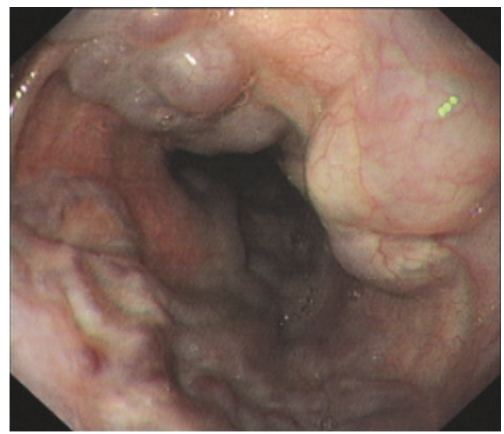

(c)

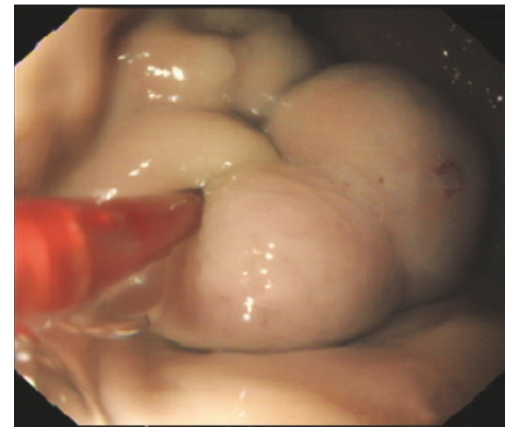

(b)

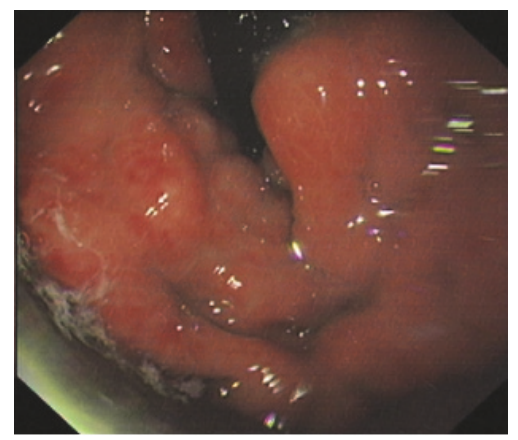

(d)

FIGURE 1: Endoscopic findings of gastroesophageal varices (IGV Type 1 and F3/GOV Type 2) with red wale sign.

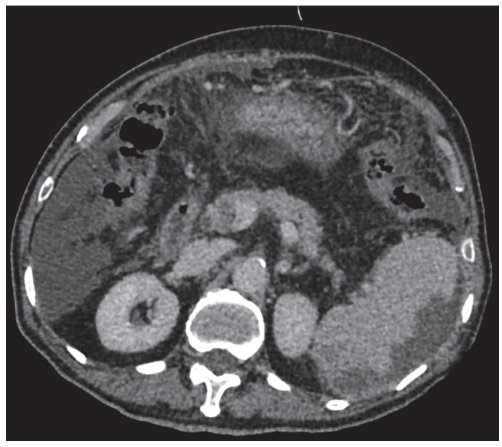

FIGURE 2: Large area splenic infarct based on CT angiography of the portal venous system.

endoscopic procedure due to a large area splenic infarct (Figure 2), confirmed via CTA of the portal venous system. Two patients (patients (3) and (5)) became lethargic and confused and experienced loss of consciousness following endotherapy. Based on clinical symptoms and cerebral MRI findings, both were diagnosed with acute cerebral infarction (Figure 3). The last patient (patient (4)) experienced pain around the umbilical region with a low-grade fever $\left(37.9^{\circ} \mathrm{C}\right)$ after the procedure. A subsequent abdominal CT and intestinal mesenteric CTA revealed intraluminal filling defects consistent with acute mesenteric ischemia (Figure 4). Detailed postoperative findings are listed in Table 2.

All patients received hemostatic medication after the endoscopic procedure as part of the standard protocol at our

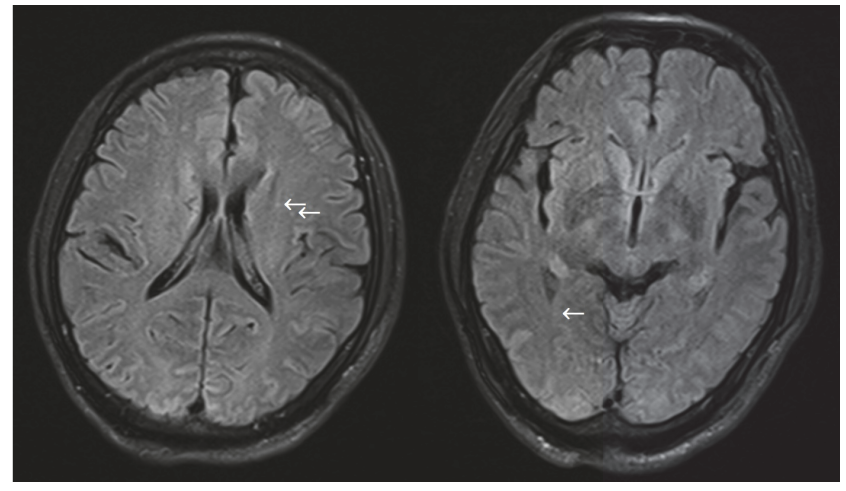

FIGURE 3: Diffuse hyperdense signals $(\leftarrow)$ on the cerebral MRI, indicative of acute cerebral infarction.

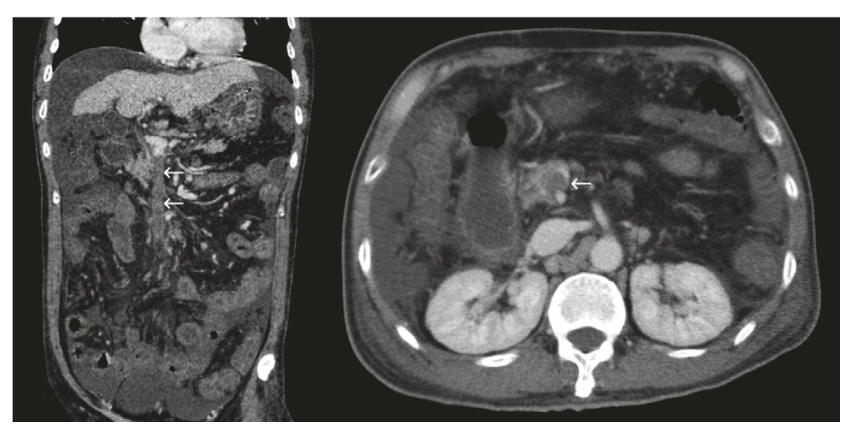

FIGURE 4: Intraluminal filling defect along the mesenteric vein and edema of the bowel wall $(\leftarrow)$. 
TABLE 2: Postoperative events including subsequent severe adverse event (SAE), patient outcome, and probable cause.

\begin{tabular}{|c|c|c|c|c|c|c|}
\hline Patient & $\begin{array}{c}\text { Postoperative } \\
\text { drug use }\end{array}$ & Adverse event & Treatment & Hospital stay & Outcome & Probable cause \\
\hline (1) & None & $\begin{array}{c}\text { Acute pulmonary } \\
\text { embolism }\end{array}$ & BCLS & 1 day & Death & $\begin{array}{l}\text { Large spontaneous } \\
\text { gastrorenal and } \\
\text { splenorenal shunt }\end{array}$ \\
\hline (2) & $\begin{array}{c}\text { Carbazochrome } \\
80 \mathrm{mg} \\
\text { Vitamin K1 } 10 \mathrm{mg} \\
\text { Somatostatin } 6 \mathrm{mg} \\
\end{array}$ & $\begin{array}{l}\text { Acute splenic } \\
\text { infarction }\end{array}$ & $\begin{array}{c}\text { Dalteparin } 5000 \mathrm{IU} \\
\text { Antibiotics } \\
\text { (meropenem + } \\
\text { vancomycin) }\end{array}$ & 64 days & Survival & $\begin{array}{l}\text { Regurgitation of tissue } \\
\text { adhesive through the } \\
\text { portovenous system or } \\
\text { probable AVM }\end{array}$ \\
\hline (3) & $\begin{array}{c}\text { Carbazochrome } \\
80 \mathrm{mg} \\
\text { Somatostatin } 3 \mathrm{mg} \\
\text { Hemocoagulase } 2 \mathrm{U}\end{array}$ & $\begin{array}{l}\text { Acute cerebral } \\
\text { infarction }\end{array}$ & $\begin{array}{c}\text { Dalteparin } 5000 \mathrm{IU} \\
\text { Edaravone } \\
\text { Mannitol } \\
\text { Dexamethasone } \\
\end{array}$ & 13 days & Survival & $\begin{array}{c}\text { Spontaneous portorenal } \\
\text { shunt }\end{array}$ \\
\hline (4) & $\begin{array}{l}\text { Hemocoagulase } 1 \mathrm{IU} \\
\text { Somatostatin } 6 \mathrm{mg}\end{array}$ & $\begin{array}{l}\text { Acute superior } \\
\text { mesenteric } \\
\text { infarction }\end{array}$ & $\begin{array}{l}\text { LMWH } 4000 \text { IU } \\
\text { Simethicone p.o. }\end{array}$ & 9 days & Death & $\begin{array}{l}\text { Regurgitation of tissue } \\
\text { adhesive through the } \\
\text { portovenous system or } \\
\text { probable AVM }\end{array}$ \\
\hline (5) & $\begin{array}{l}\text { Hemocoagulase } 1 \mathrm{IU} \\
\text { Somatostatin } 6 \mathrm{mg}\end{array}$ & $\begin{array}{l}\text { Acute cerebral } \\
\text { infarction }\end{array}$ & $\begin{array}{c}\text { LMWH } 4000 \mathrm{IU} \\
\text { Citicoline } \\
\text { GM-1 } \\
\text { Dexamethasone }\end{array}$ & 42 days & Survival & $\begin{array}{c}\text { Spontaneous } \\
\text { portoazygous shunt }\end{array}$ \\
\hline
\end{tabular}

hospital to prevent postoperative hemorrhage (Table 2). Once the patient developed signs of systemic embolization, all hemostatic agents were suspended. All patients were treated with a subcutaneous injection of low-molecular weight heparin (LMWH). Three of the four patients responded well to therapy and were subsequently discharged. Follow-up interviews confirmed survival in all three patients. However, one patient (patient (4)) developed a recurrent GI bleed, presented as melena, after 5 days of anticoagulation treatment. The patient also developed hepatic encephalopathy and deteriorated rapidly. Extraordinary life sustaining measures were refused and the patient died 9 days after the initial procedure. The overall rebleeding rate was $20 \%$ and mortality rate was $40 \%$ in the five patients who experienced SAE after cyanoacrylate injection. Of the three patients who survived (60\%), only 2 received follow-up endoscopy examination. Complete variceal obliteration was observed in one patient (50\%), while the other patient had recurrent gastroesophageal varices (GOV Type 2) treated with consolidation EBL plus cyanoacrylate injection.

A retrospective review of the radiological studies was conducted in attempt to identify a potential explanation for the occurrence of an embolic event. Three of the 5 patients had evident spontaneous portosystemic shunts upon review of imaging studies, including one case of portorenal shunt (patient (3), cerebral infarction), one case of portoazygous shunt (patient (5), cerebral infarction), and one case of concurrent portorenal and portosystemic shunt (patient (1), pulmonary embolism). The remaining cases of mesenteric and splenic infarction had no prominent vascular anomaly.

In order to further identify similar reports of adverse events in present literature, a detailed search of Medline (R), from 1946 to present with daily updates, and Embase, from 1974 to March 20, 2017, was conducted (the Appendix). A total of 43 and 119 reports were retrieved from each database, respectively. Forty-two duplicates were removed and a thorough review of title and abstract of 120 articles was performed. Ninety-seven reports were further eliminated due to irrelevance and finally 24 articles, along with 4 case reports identified from other sources, were included for the purpose of this literature review.

Of the 27 studies included, majority of reported adverse events were pulmonary embolism, 12/27 (44.44\%), and splenic infarction, 9/27 (33.33\%), while others include cases of portal vein, renal vein embolism, sclerosant extravasation, myocardial infarction, diaphragmatic embolism, cerebral infarction, right atrium emboli, esophageal variceal embolism, and subsequent septicemia or DIC. Several adverse events were attributed to cardiac abnormalities such as patent foramen ovale, prompting right-to-left shunt. Other hypotheses include volume and speed of injection or intravariceal pressure, resulting in regurgitation through the portovenous system. Interestingly, many authors presumed the presence of spontaneous portovenous shunt, such as gastrosplenorenal shunt or anomalous arteriovenous shunts, as a culprit for distant embolization. However, none of the reports provided radiological or morphological evidence of the vasculature anomaly. The results of the literature review were summarized in Table 3.

\section{Discussion}

Gastric varices are associated with a high morbidity and mortality rate in patients with portal hypertension. The current recommendation for first-line treatment is endoscopic injection of tissue adhesives. Obliteration can be achieved in one session, but sometimes repeat sessions are required [39]. Although cyanoacrylate injection has proven to be safe and effective, several reports on related adverse events have also 


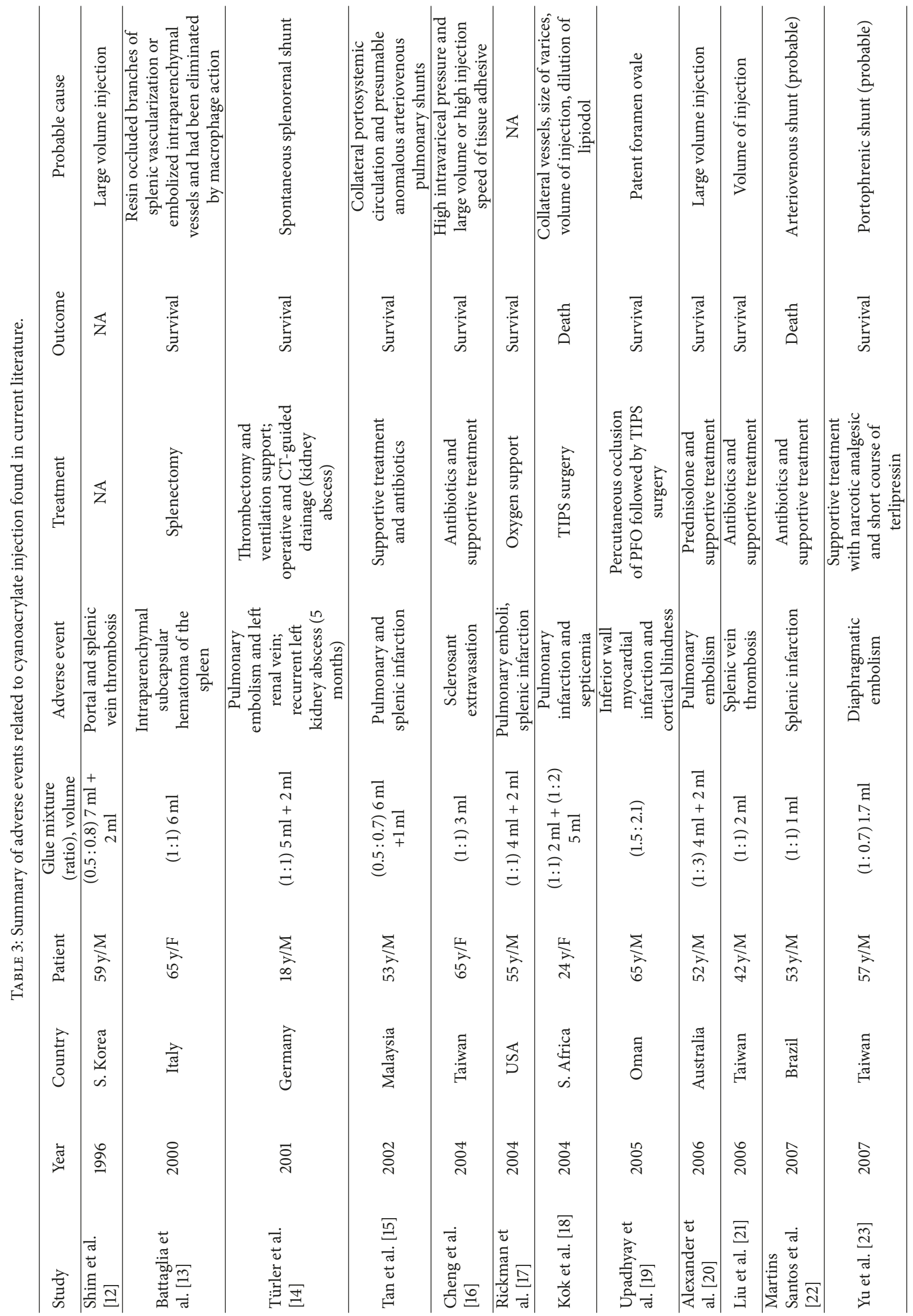




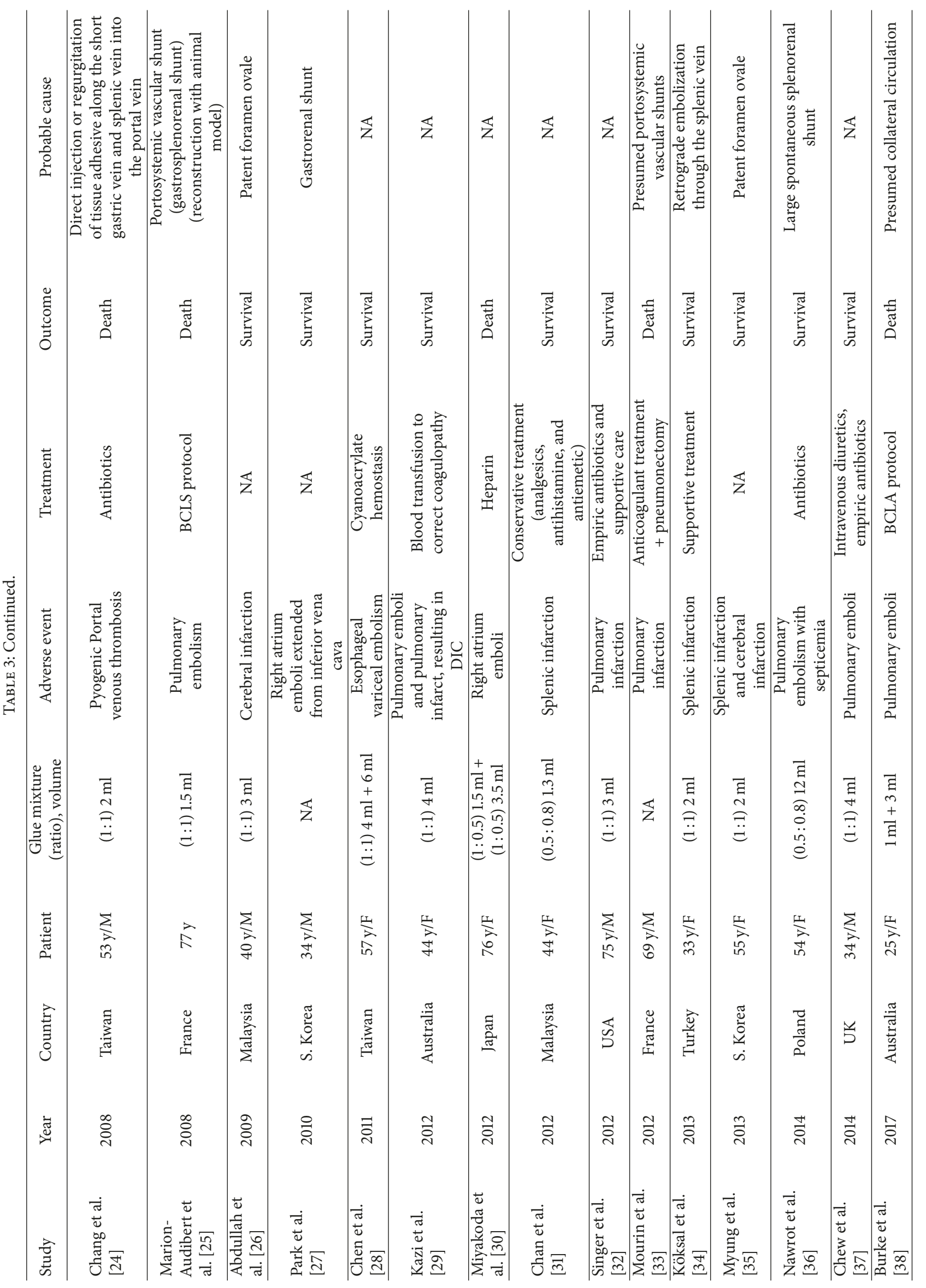




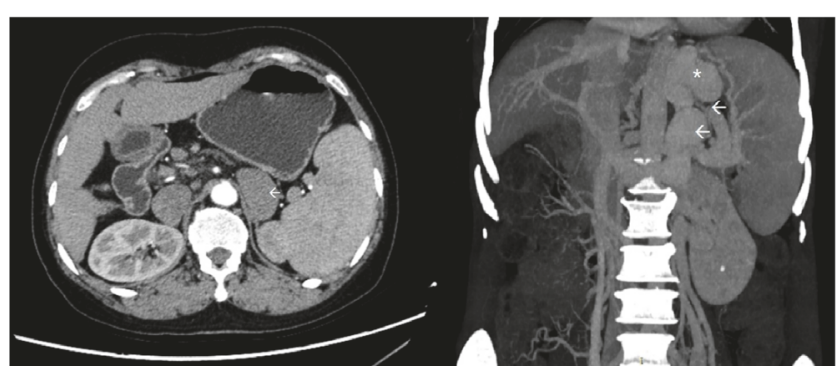

FIGURE 5: Spontaneous portosystemic shunt in the patient with IGV Type 1, presenting as portorenal and portosystemic shunt $(\leftarrow)$. The coronal view shows gastric varices $(*)$ connected to both the left renal and splenic vein through as large torturous, dilated venous shunt $(\leftarrow)$.

been documented [7]. Seewald et al. have emphasized the importance of a standardized technique, which can minimize the risk of embolization and local complications but also decrease variceal recurrence or rebleeding by effectively obliterating vessel tributaries. The recommended mixture proportion of N-butyl-2-cyanoacrylate to lipiodol is $0.5 \mathrm{ml}: 0.8 \mathrm{ml}$, and injection of over $1 \mathrm{ml}$ glue mixture may increase the risk of embolization $[8,40]$. Researchers have also explored alternative treatments for gastric varices obliteration, minimizing or eliminating the use of tissue adhesives. Tan et al. conducted a randomized control trial comparing the efficacy of gastric variceal band ligation versus cyanoacrylate injection [41]. Meanwhile, Romero-Castro et al. reported fewer complications with endoscopic ultrasound-guided coil injection compared to that of traditional cyanoacrylate injection [42].

We report five cases of adverse events that occurred after the endoscopic injection of cyanoacrylate for the treatment of gastric varices. All cases involved the formation of systemic embolus, including cerebral vascular infarction, mesenteric infarction, splenic infarction, and pulmonary embolism. A retrospective review of radiological studies revealed presence of spontaneous portosystemic shunt (SPSS) in 3 patients with distant systemic emboli, including one case of portorenal shunt, one case of portoazygous shunt, and one case of concurrent portorenal and portosplenic shunt (Figure 5). Based on the clinical presentation and radiological findings, three cases can be ascertained as glue emboli, including the case of pulmonary embolism and two cases of cerebral infarction. The formation of spontaneous portosystemic shunts (SPSS) may serve as a shortcut for acute glue embolization, which calls into question the necessity of angiographic studies prior to endoscopic intervention and whether patients with diverging shunts should be tackled with a different therapeutic approach [43]. Our center has previously performed BRTO assisted cyanoacrylate injection for patients with large gastrorenal shunt or splenorenal shunt (data reported elsewhere). This procedure prevents the occurrence of systemic glue emboli for patients with evident portosystemic shunt; however, it is poorly tolerated by patients. BRTO assisted cyanoacrylate injection requires the patient to lay in a supine position with only local anesthesia and an angiography of the portosystemic system is performed via femoral access. After the portosystemic shunt is located a balloon is deployed and secured, while the endoscopist performs the subsequent cyanoacrylate injection.

The remaining cases of mesenteric infarction and splenic infarct remain controversial and cannot be ascertained as the presence of SPSS. A plausible explanation could be due to the injection of cyanoacrylate into the arterial system, which in some cases is located adjacent to the varix or is connected via an arteriovenous malformation. Glue emboli of the splenic artery may result in a large area splenic infarct as seen in patient (2). Another explanation is the regurgitation of tissue adhesives through the portovenous system, potentially due to high speed or volume injection or high intravariceal pressure. Patients with end-stage cirrhosis are also prone to clot formation, especially in the portal venous system [44]. The use of various hemostatic agents combined with a decrease in blood flow velocity, exacerbated by a stress event (endotherapy), may also be a probable explanation for an acute thrombus formation. Unlike other studies, our center employs lauromacrogol instead of lipiodol as a diluting agent for cyanoacrylate via sandwich technique [11]. Therefore, glue embolization is difficult to differentiate from a thrombus formation on imaging studies.

Antithrombotic treatment with LMWH is a fairly standard treatment protocol. However, in cases with recent interventional procedure or hemorrhagic episode, the use of LMWH can be precarious [45]. Development of a rebleed in such patients can be just as fatal as the adverse event itself. Anticoagulants are effective in the treatment of blood thrombus; however, the effect on glue emboli or improvement of patient outcome remains questionable.

The detailed literature review provided some further insights based on case reports of embolic events experienced after cyanoacrylate injection. Many authors theorized the presence of spontaneous portosystemic shunt as a probable explanation for embolization of tissue adhesives. However, no radiological or morphological evidence of vasculature malformation was provided. In our study, we meticulously reviewed the radiological imaging of all 5 patients and were able to identify the presence of spontaneous portosystemic shunt in $3 / 5$ (60\%) subjects.

Overall, the use of cyanoacrylate for gastric variceal obliteration is widely accepted with promising results. The safety of tissue adhesive injection is often guaranteed when endoscopist abides by the standardized sandwich technique $[8,40]$. However, the necessity of preoperative imaging of the portovenous system should also be considered to identify patients with spontaneous portosystemic shunt (SPSS). In such cases, the risk of traditional endoscopic glue injection should be thoroughly vetted, or alternative treatment measures such as coil injection, TIPS, BRTO, or surgical therapy should be referred to. Utility of pre- and postoperative hemostatic agents should also be carefully considered to achieve a desirable hemostatic balance. Adverse events associated with tissue adhesives are often fatal and debilitating for patients; any red flags before endoscopic therapy should 
TABLE 4

\begin{tabular}{|c|c|c|c|c|}
\hline Number & Searches & Medline results & Embase results & Search type \\
\hline (1) & $\begin{array}{l}\text { (esophag* or esophag* } \text { gastr }^{*} \text { or gastr* esophag* }{ }^{*} \text { or } \\
\text { gastr }^{*} \text { oesophag }^{*} \text { or gastroesophag* or gastrooesophag }{ }^{*} \text { or } \\
\left.\text { oesophag* or oesophag }{ }^{*} \text { gastr }^{*} \text { or gastr }{ }^{*}\right) \text {.mp. [mp = title, abstract, } \\
\text { original title, name of substance word, subject heading word, } \\
\text { keyword heading word, protocol supplementary concept word, rare } \\
\text { disease supplementary concept word, unique identifier, synonyms] }\end{array}$ & 169513 & 268529 & Advanced \\
\hline (2) & 1 and (varic* or varix).mp. & 14601 & 21427 & Advanced \\
\hline (3) & exp esophageal varices/ & 12569 & 17997 & Advanced \\
\hline$(4)$ & exp gastric varices/ & 12569 & 2864 & Advanced \\
\hline (5) & $(3)$ or $(4)$ & 12569 & 19501 & Advanced \\
\hline (6) & (2) or (5) & 14601 & 22623 & Advanced \\
\hline (7) & $\begin{array}{l}\text { (cyanoacrylate or n-butyl-2-cyanoacrylate or NBCA or NB2CYA or } \\
\text { NB2-CYA or tissue adhesive or tissue glue or glue).mp. [mp = title, } \\
\text { abstract, original title, name of substance word, subject heading word, } \\
\text { keyword heading word, protocol supplementary concept word, rare } \\
\text { disease supplementary concept word, unique identifier, synonyms] }\end{array}$ & 13485 & 26245 & Advanced \\
\hline (8) & 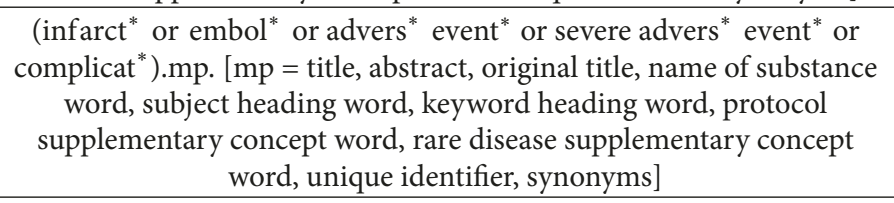 & 1649685 & 3380532 & Advanced \\
\hline (9) & (7) and (8) & 4356 & 10406 & Advanced \\
\hline (10) & $\begin{array}{c}\text { (endoscop }^{*} \text { therap }^{*} \text { or endoscop } \\
\text { [mp }=\text { title, abstract, original title, name of substance word, subject } \\
\text { heading word, keyword heading word, protocol supplementary } \\
\text { concept word, rare disease supplementary concept word, unique } \\
\text { identifier, synonyms] }\end{array}$ & 8912 & 21219 & Advanced \\
\hline (11) & (9) and (10) & 186 & 657 & Advanced \\
\hline (12) & $\begin{array}{l}\left.\text { (case or case report* or case serie* } \text { or report }^{*}\right) . \mathrm{mp} .[\mathrm{mp}=\text { title, } \\
\text { abstract, original title, name of substance word, subject heading word, } \\
\text { keyword heading word, protocol supplementary concept word, rare } \\
\text { disease supplementary concept word, unique identifier, synonyms] }\end{array}$ & 4746115 & 6342357 & Advanced \\
\hline (13) & (6) and (11) and (12) & 43 & 119 & Advanced \\
\hline
\end{tabular}

Exp, explode.

be well recognized by physicians, prompting well-rounded consideration to effectively avoid the occurrence of adverse events.

\section{Appendix}

\section{Detailed Search Strategy}

The search strategy used was Ovid Medline (R), from 1946 to present with daily updates, and Embase, from 1974 to March 20, 2017(see Table 4).

\section{Ethical Approval}

All procedures followed were in accordance with the ethical standards of the responsible committee of human experimentation (institutional and national) and with the Helsinki Declaration of 1975, as revised in 2008.

\section{Consent}

Informed consent was obtained from all patients for being included in the study.

\section{Disclosure}

The abstract of this manuscript has been presented at China 17th Congress of Gastroenterology, Xi'an, China, September 14-16, 2017. This article does not contain any studies with animal subjects.

\section{Conflicts of Interest}

Yujen Tseng, Lili Ma, Tiancheng Luo, Xiaoqing Zeng, Yichao Wei, Ling Li, Pengju Xu, and Shiyao Chen declare that they have no conflicts of interest. All procedures followed were in accordance with the ethical standards of the responsible 
committee of human experimentation (institutional and national) and with the Helsinki Declaration of 1975, as revised in 2008 .

\section{Authors' Contributions}

Yujen Tseng and Lili Ma contributed equally to the manuscript and share first authorship.

\section{Acknowledgments}

This study was supported by the Innovation Fund of Shanghai Scientific Committee (no. 15411950501).

\section{References}

[1] G. Garcia-Tsao and J. Bosch, "Management of varices and variceal hemorrhage in cirrhosis," The New England Journal of Medicine, vol. 362, no. 9, pp. 778-832, 2010.

[2] R. de Franchis, "Expanding consensus in portal hypertension: Report of the Baveno VI Consensus Workshop: Stratifying risk and individualizing care for portal hypertension," Journal of Hepatology, vol. 63, no. 3, pp. 743-52, 2015.

[3] S. K. Sarin, D. Lahoti, S. P. Saxena, N. S. Murthy, and U. K. Makwana, "Prevalence, classification and natural history of gastric varices: a long-term follow-up study in 568 portal hypertension patients," Hepatology, vol. 16, no. 6, pp. 1343-1349, 1992.

[4] N. Soehendra, V. Nam Ch., H. Grimm, and I. Kempeneers, "Endoscopic obliteration of large esophagogastric varices with bucrylate," Endoscopy, vol. 18, no. 1, pp. 25-26, 1986.

[5] S. K. Sarin and S. R. Mishra, "Endoscopic Therapy for Gastric Varices," Clinics in Liver Disease, vol. 14, no. 2, pp. 263-279, 2010.

[6] F. Weilert and K. F. Binmoeller, "Cyanoacrylate glue for gastrointestinal bleeding," Current Opinion in Gastroenterology, vol. 32, no. 5, pp. 358-364, 2016.

[7] K. F. Binmoeller, "Glue for gastric varices: Some sticky issues," Gastrointestinal Endoscopy, vol. 52, no. 2, pp. 298-301, 2000.

[8] S. Seewald, T. L. Ang, H. Imazu et al., "A standardized injection technique and regimen ensures success and safety of N-butyl2-cyanoacrylate injection for the treatment of gastric fundal varices (with videos)," Gastrointestinal Endoscopy, vol. 68, no. 3, pp. 447-454, 2008.

[9] D. S. Rengstoff and K. F. Binmoeller, "A pilot study of 2-octyl cyanoacrylate injection for treatment of gastric fundal varices in humans," Gastrointestinal Endoscopy, vol. 59, no. 4, pp. 553$558,2004$.

[10] Y. Idezuki, "General rules for recording endoscopic findings of esophagogastric varices (1991)," World Journal of Surgery, vol. 19, no. 3, pp. 420-422, 1995.

[11] X. Zeng, L. Ma, Y. Tzeng et al., "Endoscopic cyanoacrylate injection with or without lauromacrogol for gastric varices: a randomized pilot study," Journal of Gastroenterology and Hepatology, vol. 32, no. 3, pp. 631-638, 2017.

[12] C. S. Shim, Y. D. Cho, J. O. Kim et al., "A case of portal and splenic vein thrombosis after histoacryl injection therapy in gastric varices," Endoscopy, vol. 28, no. 5, p. 461, 1996.

[13] G. Battaglia, T. Morbin, E. Patarnello, C. Merkel, M. C. Corona, and E. Ancona, "Visceral fistula as a complication of endoscopic treatment of esophageal and gastric varices using isobutyl-2cyanoacrylate: Report of two cases," Gastrointestinal Endoscopy, vol. 52, no. 2, pp. 267-270, 2000.
[14] A. Türler, M. Wolff, D. Dorlars, and A. Hirner, "Embolic and septic complications after sclerotherapy of fundic varices with cyanoacrylate," Gastrointestinal Endoscopy, vol. 53, no. 2, pp. 228-230, 2001

[15] Y. M. Tan, K. L. Goh, A. Kamarulzaman et al., "Multiple systemic embolisms with septicemia after gastric variceal obliteration with cyanoacrylate," Gastrointestinal Endoscopy, vol. 55, no. 2, pp. 276-278, 2002.

[16] H. C. Cheng, P. N. Cheng, Y. M. Tsai, H. M. Tsai, and C. Y. Chen, "Sclerosant extravasation as a complication of sclerosing endotherapy for bleeding gastric varices," Endoscopy, vol. 36, no. 3, pp. 239-241, 2004.

[17] O. B. Rickman, J. P. Utz, G. L. Aughenbaugh, and C. J. Gostout, "Pulmonary embolization of 2-octyl cyanoacrylate after endoscopic injection therapy for gastric variceal bleeding," Mayo Clinic Proceedings, vol. 79, no. 11, pp. 1455-1458, 2004.

[18] K. Kok, R. P. Bond, I. C. Duncan et al., "Distal embolization and local vessel wall ulceration after gastric obliteration with $\mathrm{N}$ butyl-2-cyanoacrylate: A case report and review of the literature," Endoscopy, vol. 36, no. 5, pp. 442-446, 2004.

[19] A. P. Upadhyay, R. Ananthasivan, S. Radhakrishnan, and G. Zubaidi, "Cortical blindness and acute myocardial infarction following injection of bleeding gastric varices with cyanoacrylate glue," Endoscopy, vol. 37, no. 10, p. 1034, 2005.

[20] S. Alexander, M. G. Korman, and W. Sievert, "Cyanoacrylate in the treatment of gastric varices complicated by multiple pulmonary emboli," Internal Medicine Journal, vol. 36, no. 7, pp. 462-465, 2006.

[21] C. H. Liu, F. C. Tsai, P. C. Liang, C. Z. Lee, and P. M. Yang, "Splenic vein thrombosis and Klebsiella pneumoniae septicemia after endoscopic gastric variceal obturation therapy with N-butyl-2-cyanoacrylate," Gastrointestinal Endoscopy, vol. 63, no. 2, pp. 336-338, 2006.

[22] M. M. Martins Santos, L. P. Correia, R. A. Rodrigues, L. H. Lenz Tolentino, A. P. Ferrari, and E. D. Libera, "Splenic artery embolization and infarction after cyanoacrylate injection for esophageal varices," Gastrointestinal Endoscopy, vol. 65, no. 7, pp. 1088-1090, 2007.

[23] C. F. Yu, L. W. Lin, S. W. Hung, C. T. Yeh, and C. F. Chong, "Diaphragmatic embolism after endoscopic injection sclerotherapy for gastric variceal bleeding," The American Journal of Emergency Medicine, vol. 25, no. 7, pp. 860-e6, 2007.

[24] C. J. Chang, Y. T. Shiau, T. L. Chen et al., "Pyogenic portal vein thrombosis as a reservoir of persistent septicemia after cyanoacrylate injection for bleeding gastric varices," Digestion, vol. 78, no. 2-3, pp. 139-143, 2008.

[25] A. M. Marion-Audibert, M. Schoeffler, F. Wallet et al., "Acute fatal pulmonary embolism during cyanoacrylate injection in gastric varices," Gastroentérologie Clinique et Biologique, vol. 32, no. 11, pp. 926-930, 2008.

[26] A. Abdullah, S. Sachithanandan, O. K. Tan et al., "Cerebral embolism following N-butyl-2-cyanoacrylate injection for esophageal postbanding ulcer bleed: A case report," Hepatology International, vol. 3, no. 3, pp. 504-508, 2009.

[27] J. S. Park, J. J. Park, S. K. Lim et al., "Long journey of sclerosant from the esophagus to the right atrium," Korean Circulation Journal, vol. 40, no. 9, pp. 468-470, 2010.

[28] P. H. Chen, M. C. Hou, H. C. Lin, and S. D. Lee, “Cyanoacrylate embolism from gastric varices may lead to esophageal variceal rupture," Endoscopy, vol. 43, no. 2, pp. E149-E150, 2011.

[29] S. Kazi, M. Spanger, and J. Lubel, "Gastrointestinal: Pulmonary embolism of cyanoacrylate glue following endoscopic injection 
of gastric varices," Journal of Gastroenterology and Hepatology, vol. 27 , no. 12, pp. 1874-1874, 2012.

[30] K. Miyakoda, H. Takedatsu, K. Emori et al., "N-butyl-2-cyanoacrylate (histoacryl) glue in the right atrium after endoscopic injection for a ruptured duodenal varix: Complication of histoacryl injection," Digestive Endoscopy, vol. 24, no. 3, p. 192, 2012.

[31] R. S. Chan, A. Vijayananthan, G. Kumar, and I. N. Hilmi, "Imaging findings of extensive splenic infarction after cyanoacrylate injection for gastric varices-a case report," Malaysian Medical Association, pp. 424-425, 2012.

[32] A. D. Singer, G. Fananapazir, F. Maufa, S. Narra, and S. Ascher, "Pulmonary embolism following 2-octyl-cyanoacrylate/lipiodol injection for obliteration of gastric varices: An imaging perspective," Journal of Radiology Case Reports, vol. 6, no. 2, pp. 17-22, 2012.

[33] G. Mourin, A. Badia, A. Cazes, and B. Planquette, "An unusual cause of pulmonary artery pseudoaneurysm: Acrylate embolism," Interactive CardioVascular and Thoracic Surgery, vol. 15, no. 6, pp. 1082-1084, 2012.

[34] A. Ş. Köksal, E. Kayaçetin, S. Torun, V. Erkan, and R. S. Ökten, "Splenic infarction after N-butyl-2-cyanoacrylate injection for gastric varices: Why does it happen?" Surgical Laparoscopy Endoscopy \& Percutaneous Techniques, vol. 23, no. 5, pp. e191e193, 2013.

[35] D. S. Myung, C. Y. Chung, H. C. Park et al., "Cerebral and splenic infarctions after injection of N-butyl-2-cyanoacrylate in esophageal variceal bleeding," World Journal of Gastroenterology, vol. 19, no. 34, pp. 5759-5762, 2013.

[36] I. Nawrot, T. Cieciura, B. Morawski, and P. J. U. Malkowski, "Pulmonary embolism with septicemia after N-butyl-2cyanoacrylate injection for bleeding gastric varices," Chinese Medical Journal, 2014.

[37] J. R. Y. Chew, A. Balan, W. Griffiths, and J. Herre, "Delayed onset pulmonary glue emboli in a ventilated patient: A rare complication following endoscopic cyanoacrylate injection for gastric variceal haemorrhage," BMJ Case Reports, vol. 2014, Article ID 206461, 2014.

[38] M. P. Burke, C. O’Donnell, and Y. Baber, "Death from pulmonary embolism of cyanoacrylate glue following gastric varix endoscopic injection," Forensic Science, Medicine and Pathology, vol. 13, no. 1, pp. 82-85, 2017.

[39] S. K. Sarin and A. Kumar, "Endoscopic Treatment of Gastric Varices," Clinics in Liver Disease, vol. 18, no. 4, pp. 809-827, 2014.

[40] S. Seewald, P. V. J. Sriram, M. Naga et al., "Cyanoacrylate glue in gastric variceal bleeding," Endoscopy, vol. 34, no. 11, pp. 926932, 2002.

[41] P. C. Tan, M. C. Hou, H. C. Lin et al., "A randomized trial of endoscopic treatment of acute gastric variceal hemorrhage: $\mathrm{N}$ butyl-2-cyanoacrylate injection versus band ligation," Hepatology, vol. 43, no. 4, pp. 690-697, 2006.

[42] R. Romero-Castro, M. Ellrichmann, C. Ortiz-Moyano et al., "EUS-guided coil versus cyanoacrylate therapy for the treatment of gastric varices: A multicenter study (with videos)," Gastrointestinal Endoscopy, vol. 78, no. 5, pp. 711-721, 2013.

[43] M. Takashi, M. Igarashi, S. Hino et al., "Portal hemodynamics in chronic portal-systemic encephalopathy - Angiographic study in seven cases," Journal of Hepatology, vol. 1, no. 5, pp. 467-476, 1985.

[44] F. Nery, S. Chevret, B. Condat et al., "Causes and consequences of portal vein thrombosis in 1,243 patients with cirrhosis: results of a longitudinal study," Hepatology, vol. 61, no. 2, pp. 660-667, 2015.

[45] A. Andriulli, A. Tripodi, P. Angeli et al., "Hemostatic balance in patients with liver cirrhosis: report of a consensus conference," Digestive and Liver Disease, vol. 48, no. 5, pp. 455-467, 2016. 


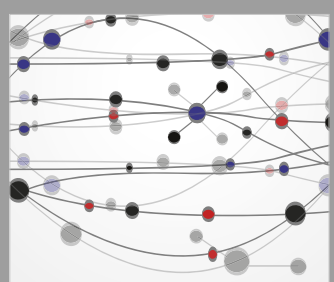

The Scientific World Journal
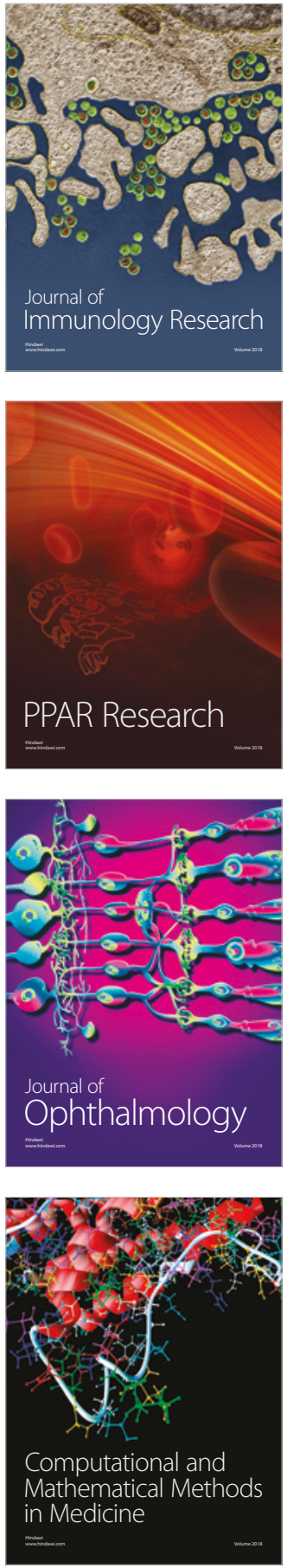

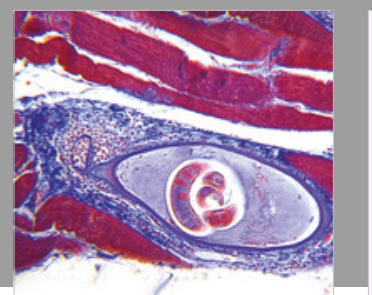

Gastroenterology Research and Practice

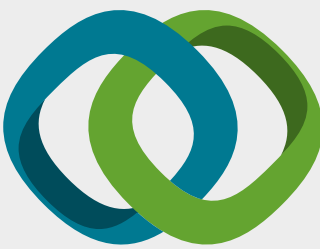

\section{Hindawi}

Submit your manuscripts at

www.hindawi.com
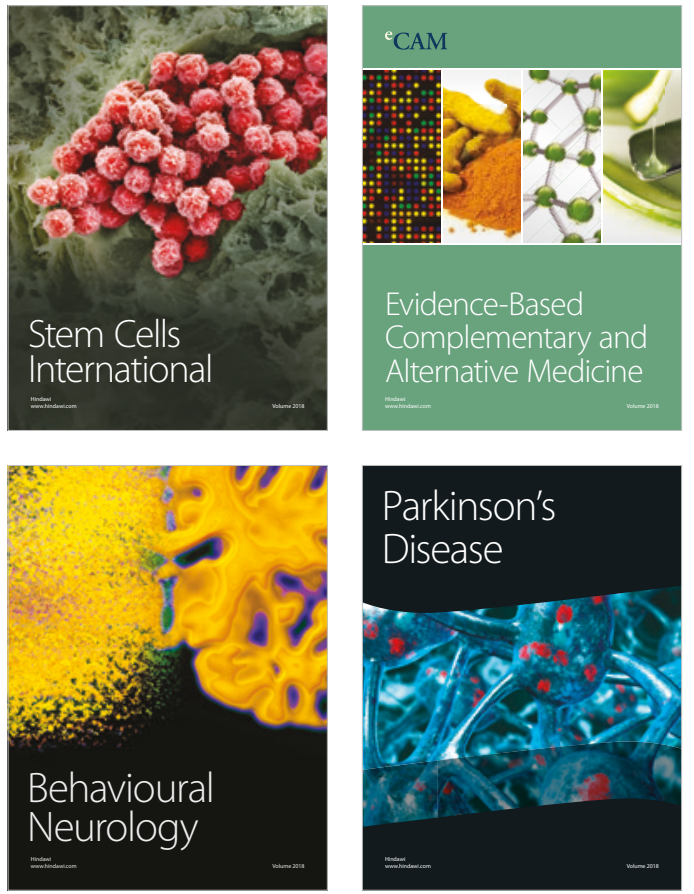

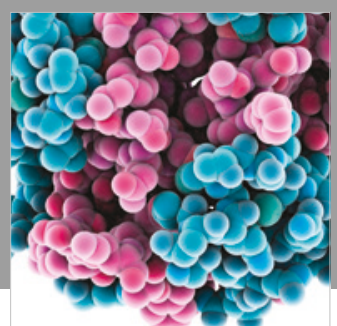

ournal of

Diabetes Research

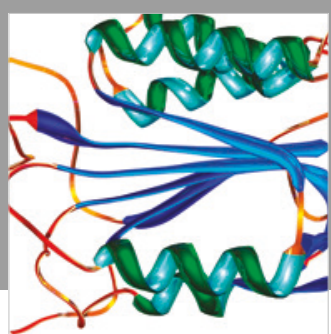

Disease Markers
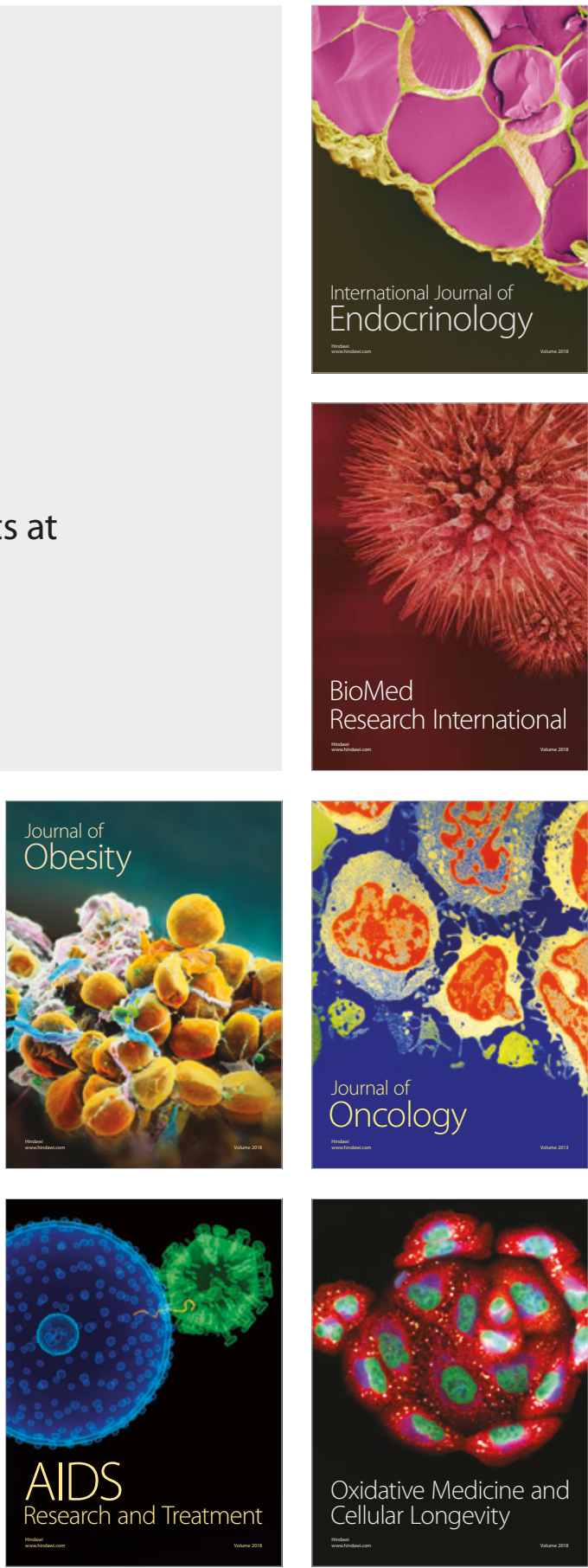